\title{
Isolation of Chromosome Clusters from Metaphase-arrested HeLa Cells
}

\author{
James R. Paulson \\ Laboratory of Molecular Biology, The MRC Centre, Hills Road, Cambridge CB2 2QH, England; \\ present address: Biophysics Research Division, Institute of Science and Technology, \\ University of Michigan, Ann Arbor, Michigan 48109, U.S.A.
}

\begin{abstract}
We have developed a simplified approach for the isolation of metaphase chromosomes from HeLa cells. In this method, all the chromosomes from a cell remain together in a bundle which we call a "metaphase chromosome cluster". Cells are arrested to $90-95 \%$ in metaphase, collected by centrifugation, extracted with non-ionic detergent in a low ionic strength buffer at neutral $\mathrm{pH}$, and homogenised to strip away the cytoskeleton. The chromosome clusters which are released can then be isolated in a crude state by pelleting or they can be purified away from nearly all the interphase nuclei and cytoplasmic debris by banding in a Percoll ${ }^{\mathrm{TM}}$ density gradient. - This procedure has the advantages that it is quick and easy, metaphase chromatin is recovered in high yield, and $\mathrm{Ca}^{++}$is not needed to stabilise the chromosomes. Although the method does not yield individual chromosomes, it is nevertheless very useful for both structural and biochemical studies of mitotic chromatin. The chromosome clusters also make possible biochemical and structural studies of what holds the different chromosomes together. Such information could be useful in improving chromosome isolation procedures and for understanding suprachromosomal organisation of the nucleus.
\end{abstract}

\section{Introduction}

In the past 20 years a number of methods have been developed for the isolation of eukaryotic metaphase chromosomes. These preparations have proved very useful in studies of chromosome structure (e.g. Stubblefield and Wray, 1971; Paulson and Laemmli, 1977; Marsden and Laemmli, 1979; Goyannes et al., 1980) and in biochemical studies of the changes in chromatin throughout the cell cycle (e.g., Matsui et al., 1979a, b). Metaphase chromosomes have also been useful in genetic mapping, for example in gene transfer experiments (e.g. Klobutcher and Ruddle, 1979; McBride and Peterson, 1980) and in construction of cloned genomic libraries of individual chromosomes (Davies et al., 1981).

Early methods for the isolation of metaphase chromosomes were reviewed 
by Hanson (1975), and since then procedures have been described by Wullems et al. (1975), Horikawa and Sakamoto (1977), Maio and Schildkraut (1978), Jeppeson et al. (1978), Blumenthal et al. (1979), Marsden and Laemmli (1979), Adolph (1980) and Goyannes et al. (1980). Although these methods have used a wide variety of $\mathrm{pH}$ and other solution conditions, they have all had the aim of producing individual chromosomes, and all have used the following basic approach. First, partial synchrony is induced in the cells by treatment with spindle poisons such as colchicine, vinblastine or nocodazole which arrest cells in metaphase. Second, cells are pretreated, usually hypotonically, to separate the chromosomes from one another. Third, the cells are broken with detergent and/or gentle homogenisation which frees the chromosomes from one another and from cell debris. Finally, the individual chromosomes are separated from interphase nuclei and unlysed cells on one hand, and from soluble cell components and debris on the other, by differential centrifugation, by sedimentation in sucrose gradients or by filtration through filters of appropriate pore sizes.

In this paper, we describe a different approach to metaphase chromosome isolation, in which all the chromosomes from a single metaphase-arrested HeLa cell remain together in a bundle which we call a "metaphase chromosome cluster", or simply a "chromosome cluster". Others have observed these clusters before, but they have previously been viewed as aggregates and as obstacles to the isolation of individual chromosomes, without considering their potential usefulness or possible biological significance.

Although individual chromosomes are obviously important for some purposes, chromosome clusters are perfectly adequate for biochemical and structural studies of bulk metaphase chromatin, and indeed have several advantages. Chromosome clusters have been useful in low-angle X-ray diffraction studies of metaphase chromosomes (J.R. Paulson and J. Langmore and Schutt, manuscript in preparation), in studies of phosphorylation of chromosomal proteins (Paulson, 1980; Paulson and Taylor, 1982) and in other biochemical studies (Lund et al. 1981).

\section{Materials and Methods}

Cell Culture. HeLa S3 cells were grown in suspension in RPMI-1640 medium supplemented with $5 \%$ newborn calf serum (heat inactivated), $100 \mathrm{U} / \mathrm{ml}$ penicillin and $100 \mu \mathrm{g} / \mathrm{ml}$ streptomycin, or in Eagles minimum essential medium with Earles' salts supplemented with calf serum, penicillin and streptomycin (as above) and in addition $1 \mathrm{mM}$ pyruvate and non-essential amino acids. Tissue culture media and components were obtained from Flow Laboratories. Cultures were diluted daily to $2.0 \times 10^{5}$ cells $/ \mathrm{ml}$.

To arrest cells in metaphase, cultures at $2.5 \times 10^{5}$ cells $/ \mathrm{ml}$ were treated with $2.5 \mathrm{mM}$ thymidine (Xeros, 1962) for $20-24 \mathrm{~h}$, after which the cells were pelleted, washed with $0.9 \% \mathrm{NaCl}$ solution and resuspended in half the original volume of fresh medium. $0.1 \mu \mathrm{g} / \mathrm{ml}$ Colcemid (Sigma) or $0.25 \mu \mathrm{g} / \mathrm{ml}$ Nocodazole (Aldrich; stock solution $5 \mathrm{mg} / \mathrm{ml}$ in dimethylsulfoxide) was added after $4-6 \mathrm{~h}$ and the cells were harvested at $16-20 \mathrm{~h}$ after release of the thymidine block. This procedure gave $90-95 \%$ metaphase cells.

Isolation of Metaphase Chromosomes. Three different methods were used to isolate metaphase chromosomes, which will be referred to as Hexylene Glycol chromosomes, Aqueous Chromosomes and Spermidine Chromosomes, respectively. 
Hexylene-glycol chromosomes were isolated by a modification of the method of Wray and Stubblefield (1970), as described by Paulson (1980). The isolation buffer consisted of $0.1 \mathrm{mM}$ Pipes (1,4-piperazine ethanesulfonic acid) $\mathrm{pH} 6.7,1 \mathrm{M}$ hexylene glycol (2-methylpentan-2,4-diol), and $0.5 \mathrm{mM} \mathrm{CaCl}_{2}$.

Aqueous chromosomes were isolated by the method of Marsden and Laemmli (1979), except using modified reticulocyte standard buffer containing $10 \mathrm{mM}$ Hepes [4-(-hydroxyethyl)-1-piperazineethanesulfonate] $\mathrm{pH} 7.2$ (instead of Tris), $10 \mathrm{mM} \mathrm{NaCl}$ and $5 \mathrm{mM} \mathrm{MgCl}$.

Spermidine chromosomes were isolated by a modification of the method of Lewis and Laemmli (manuscript in preparation). About $5 \times 10^{7}$ cells were pelleted and washed three times in $15 \mathrm{ml}$ $0.5 \times$ buffer $A$ at room temperature. (Buffer A consists of $15 \mathrm{mM}$ Tris [hydroxymethyl] aminomethane chloride pH 7.4, $0.2 \mathrm{mM}$ spermine, $0.5 \mathrm{mM}$ spermidine, $2 \mathrm{mM} \mathrm{K}$-EDTA, $80 \mathrm{mM} \mathrm{KCl}$.) The pellet was then resuspended in $15 \mathrm{ml}$ cold $\mathrm{A}+0.1 \%$ digitonin, mixed briefly on a Vortex-Genie (Scientific Industries Inc., Springfield, Mass.) and transferred to a Dounce tissue homogeniser (Wheaton Glass) with loose-fitting (type B) pestle for 10 strokes. Nuclei were removed by sedimentation at $150 \times \mathrm{g}$ for $5 \mathrm{~min}$, and chromosomes were sedimented through a $20 \mathrm{ml}$ cushion at $1,000 \times \mathrm{g}$ for $15 \mathrm{~min}$. The cushion consisted of two layers: $5 \mathrm{ml} \mathrm{A}+1.2 \mathrm{M}$ sucrose $+0.1 \%$ digitonin, and $15 \mathrm{ml} \mathrm{A}_{\mathrm{s}}(5 \mathrm{mM}$ Tris-Cl pH 7.4, $0.25 \mathrm{mM}$ spermidine, $2 \mathrm{mM} \mathrm{K-EDTA,} 2 \mathrm{mM} \mathrm{KCl})+0.3 \mathrm{M}$ sucrose $+0.1 \%$ digitonin. Finally, chromosomes were resuspended in $\mathrm{A}+0.1 \%$ digitonin. Digitonin was prepared as a $10 \%$ solution in water shortly before use by heating at $100^{\circ} \mathrm{C}$ for $10 \mathrm{~min}$.

Isolation of Crude Metaphase Chromosome Clusters. The isolation buffer (IB) for metaphase chromosome clusters consisted of $10 \mathrm{mM}$ Hepes $\mathrm{pH} 7.2,10 \mathrm{mM} \mathrm{NaCl}$ and $5 \mathrm{mM} \mathrm{MgCl}_{2}$. Cells arrested to $90-95 \%$ in metaphase were chilled $30 \mathrm{~min}$ on ice, collected by centrifugation, washed twice with cold $0.9 \% \mathrm{NaCl}$ solution and then resuspended to no more than $10^{7}$ cells $/ \mathrm{ml}$ in lysis solution consisting of IB $+0.5 \mathrm{M}$ sucrose $+0.1 \%$ Nonidet P40 (NP40). The suspension was drawn up and down twice in a $10 \mathrm{ml}$ pipette to disperse the cells, then transferred to a Dounce tissue homogeniser with tight-fitting (type A) pestle for 5-10 strokes. The downward stroke was carried out slowly and the upward stroke was vigorous. In general, the procedure was monitored by phase contrast light microscopy to be sure that the chromosome clusters were freed from the cytoskeletons. The lysate was layered over a $10 \mathrm{ml}$ cushion containing IB $+0.1 \% \mathrm{NP} 40 \%+1.2 \mathrm{M}$ sucrose and the chromosome clusters were pelleted by centrifugation in a swinging bucket rotor at $250 \times \mathrm{g}$ for $10 \mathrm{~min}$. Finally, the chromosome clusters were resuspended and washed in IB $+0.1 \% \mathrm{NP} 40$.

Purification of Chromosome Clusters on Percoll ${ }^{\mathrm{TM}}$ Density Gradients. Percoll (Pertoft et al., 1978) was obtained from Pharmacia as a solution which we refer to as " $100 \%$ Percoll". The density gradient solution consisted of $60 \%$ Percoll, $10 \mathrm{mM}$ Hepes pH 7.2, $10 \mathrm{mM} \mathrm{NaCl}, 10 \mathrm{mM} \mathrm{MgCl}$, $0.5 \mathrm{M}$ sucrose and $0.1 \% \mathrm{NP} 40$. Density gradients were preformed by centrifugation of $40 \mathrm{ml}$ of this solution in a $50 \mathrm{ml}$ polycarbonate tube for $40 \mathrm{~min}$ at $20,000 \mathrm{rpm}$ in an MSE $8 \times 50$ rotor.

Chromosome clusters were isolated as described above, resuspended in $10 \mathrm{ml}$ of solution from the top of the preformed gradient, homogenised with a Dounce tissue homogeniser and layered on top of the remaining $30 \mathrm{ml}$ gradient. Alternatively, the cells were lysed as described above except in the $10 \mathrm{ml}$ of solution taken from the top of the gradient, and this lysate was layered directly on the Percoll gradient. Centrifugation was at $1,600 \times \mathrm{g}$ for $1 \mathrm{~h}$. Chromosome clusters accumulate in a band $2-3 \mathrm{~cm}$ from the bottom of the tube, while nuclei and cell debris remain near the top. The chromosome cluster band was removed, diluted with IB $+0.1 \%$ NP40 and the chromosome clusters pelleted. They were afterwards washed several times in the same buffer to remove as much as possible of the Percoll.

Electrophoresis of Protein in Polyacrylamide Gels. Dodecylsulfate/polyacrylamide gel electrophoresis was run in gels containing 15\% acrylamide, as described by Laemmli and Favre (1973). Molecular weight markers included phosphorylase A $(95 \mathrm{k})$, bovine serum albumin $(60 \mathrm{k})$, catalase $(58 \mathrm{k})$, aldolase $(40 \mathrm{k})$, carbonic anhydrase $(29 \mathrm{k})$ and egg-white lysozyme $(14.3 \mathrm{k})$. Purified rabbit muscle actin and human blood platelets were gifts from Dr. Hattie Harris.

For acid/urea gels, the system of disc electrophoresis at pH 4.4 of Reisfeld et al. (1962) was adapted, as described in detail by Paulson (1980). 


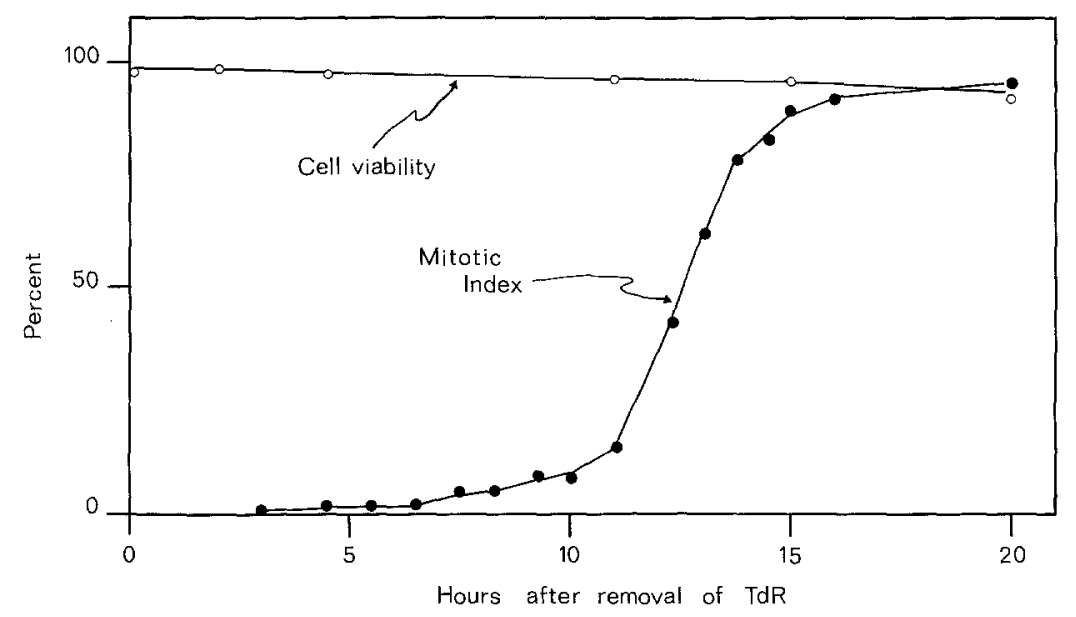

Fig. 1. Accumulation of HeLa cells in metaphase after release of a thymidine block, showing the percentage of cells which were viable _- O-_ (assayed by Trypan blue exclusion), and the percentage of viable cells in metaphase - -

\section{Results and Discussion}

\section{Preparation of Metaphase Chromosome Clusters}

Conventional methods for isolating metaphase chromosomes depend on separating the individual chromosomes from one another so that they can be separated from interphase nuclei on the basis of size. We reasoned, however, that if cell cultures were arrested to $90-95 \%$ metaphase, this would not be necessary. One could use a simpler procedure, allowing the metaphase chromosomes to remain together in bundles, and still expect only $5-10 \%$ contamination by interphase nuclei.

HeLa cells were first synchronised in S-phase by treatment with $2.5 \mathrm{mM}$ thymidine for $20 \mathrm{~h}$. Thymidine was then removed by pelleting the cells, washing with saline and resuspending in fresh medium. The thymidine block can also be reversed by adding $2.5 \mathrm{mM}$ deoxycytidine (Xeros, 1962) but in this case entry into metaphase is delayed $2-3 \mathrm{~h}$ with respect to the other method. After release of the thymidine block, cultures were treated with Colcemid or nocodazole and reached a mitotic index of $90-95 \%$ within $16-20 \mathrm{~h}$ (Fig. 1).

Once cells were arrested in metaphase, crude chromosome clusters were isolated as described in Materials and Methods. This involves three main steps: first, cells are lysed in low ionic strength buffer containing $0.5 \mathrm{M}$ sucrose and $0.1 \%$ NP40 (or $0.1 \% \mathrm{NP} 40+0.05 \%$ sodium deoxycholate), giving "detergentextracted cells" as shown in Fig. $2 \mathrm{a}$ and b. Second, the detergent-extracted cells are sheared with a Dounce tissue homogeniser to strip the cytoskeleton away from the chromosome bundles. Finally, the chromosome clusters are pelleted through a cushion containing $1.2 \mathrm{M}$ sucrose and resuspended in buffer (Fig. 2c and d).

Note that this procedure uses basically the same solutions as are used in the aqueous method of chromosome isolation published by Marsden and Laemmli (1979), except that $\mathrm{Ca}^{++}$can be omitted without affecting the stability 

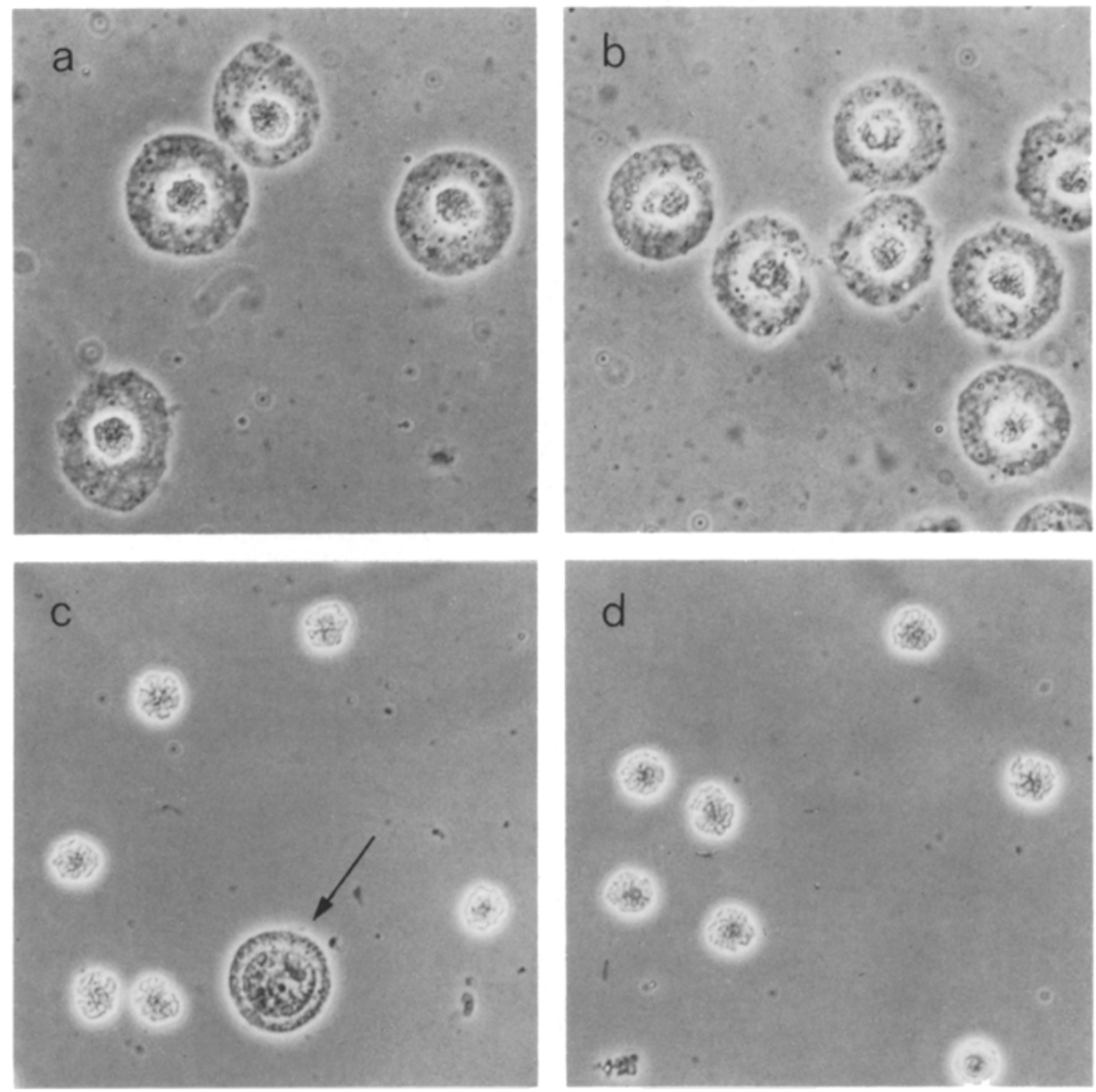

Fig. 2a-d. Stages in the isolation of metaphase chromosome clusters. (a), (b), HeLa cells after extraction with $0.1 \% \mathrm{NP} 40$ in IB $+0.5 \mathrm{M}$ sucrose. (c), (d), chromosome clusters after homogenisation of the detergent-extracted cells, pelleting and resuspension. The arrow indicates a contaminating interphase nucleus from which the cytoskeleton has not been stripped away

of the chromosomes. We have not systematically investigated other ionic conditions, but more than $20-50 \mathrm{mM} \mathrm{Na}^{+}$or $\mathrm{K}^{+}$must be avoided, since it apparently causes the chromosomes to aggregate irreversibly with cytoskeletal debris.

\section{Purification of Chromosome Clusters on Percoll Density Gradients}

Crude chromosome clusters are very useful for some purposes (see e.g. Paulson and Taylor, 1982), but their purity with respect to interphase nuclei is only as good as the synchrony of the cells. In other words, a typical preparation contains $90-95 \%$ metaphase chromatin and $5-10 \%$ interphase chromatin. Several methods to separate chromosome clusters from nuclei were therefore tested and the most successful method involves the use of Percoll.

Metaphase chromosome clusters can be efficiently purified away from interphase nuclei by sedimentation in Percoll density gradients (see Materials and 


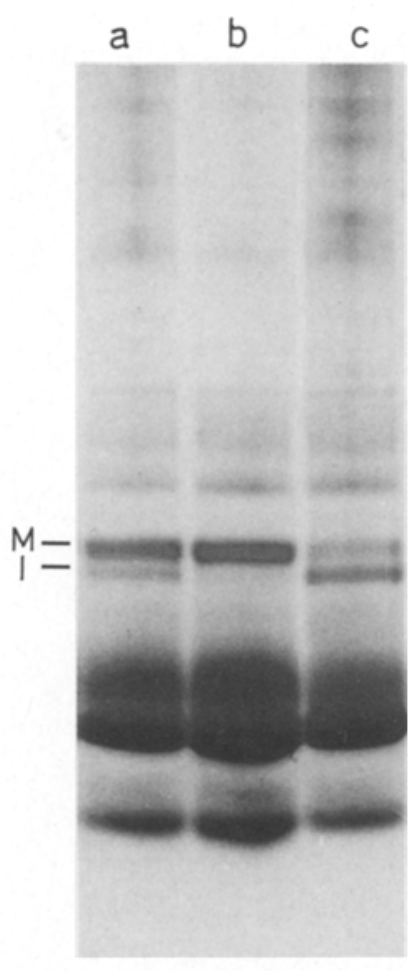

Fig. 3a-c. Purity of metaphase chromosome clusters with respect to interphase nuclei, judged by the phosphorylation state of H1. Clusters were isolated in the presence of $5 \mathrm{mM} \mathrm{C} \mathrm{HgPhSO}_{3}$ which prevents dephosphorylation of $\mathrm{H} 1$ (Paulson, 1980), extracted with $0.2 \mathrm{M} \mathrm{H}_{2} \mathrm{SO}_{4}$ and analysed on an acid/urea gel.

(a) Crude chromosome clusters;

(b) chromosome clusters from the same preparation but purified on a Percoll density gradient;

(c) material which remained at the top of the Percoll gradient.

$M$ and $I$ indicate positions of the metaphase (phosphorylated) and interphase (non-phosphorylated) histone $\mathrm{H} 1$, respectively

Methods). Most of the chromosome clusters collect $2-3 \mathrm{~cm}$ from the bottom of the tube, while most of the interphase nuclei remain near the top. Apparently, the nuclei are more buoyant because the Percoll particles, which are 250-300 $\AA$ in diameter (Pertoft et al., 1978), do not penetrate them. Some chromosome clusters, apparently entrapped in insoluble cytoplasmic debris, also remain at the top. A few nuclei are found with the chromosome clusters near the bottom of the gradient but these may be nuclei which have been damaged or have for some other reason become permeable to Percoll particles.

The purity of metaphase chromosomes with respect to interphase nuclei can be quantitated by isolating the chromosomes in the presence of $\mathrm{p}$-chloromercuriphenylsulfonate $\left(\mathrm{ClHgPhSO}_{3}\right)$ and analysing the phosphorylation state of histone H1 on acid/urea gels (Paulson, 1980). Since 100\% of H1 molecules are phosphorylated in metaphase chromosomes, the proportion of contaminating interphase nuclei is shown by the relative amount of interphase (non-phosphorylated) $\mathrm{H} 1$. The use of $\mathrm{ClHgPhSO}_{3}$ is necessary to prevent dephosphorylation of $\mathrm{H} 1$ which would otherwise occur during isolation of metaphase chromosomes (Paulson, 1980).

In order to judge the purity of metaphase chromatin from Percoll density gradients, chromosome clusters were isolated in the presence of $5 \mathrm{mM}$ $\mathrm{C} 1 \mathrm{HgPhSO}_{3}$, and proteins were extracted with $0.2 \mathrm{M} \mathrm{H}_{2} \mathrm{SO}_{4}$ and analysed on an acid/urea gel. Figure 3 a shows the pattern for crude chromosome clusters, 

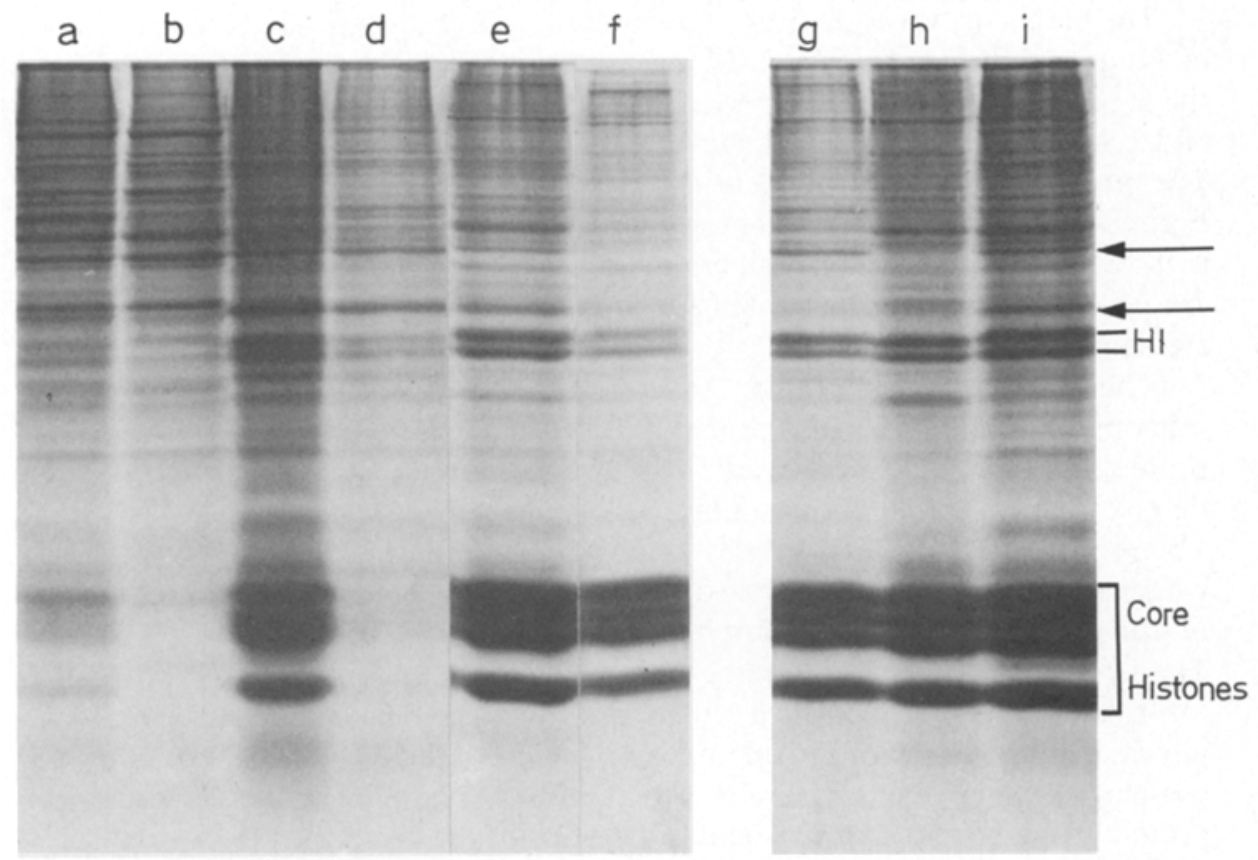

Fig. 4a-i. Sodium dodecylsulfate/polyacrylamide gel electrophoresis showing steps in the preparation of chromosome clusters, and comparing chromosome clusters with metaphase chromosomes isolated by other procedures. (a) Whole HeLa metaphase cells; (b) Proteins extracted with $0.1 \%$ NP40 in IB $+0.5 \mathrm{M}$ sucrose; (c) Proteins remaining after treatment with $0.1 \% \mathrm{NP} 40$ in IB $+0.5 \mathrm{M}$ sucrose (i.e. detergent-extracted cells); (d) Proteins removed by homogenisation of detergent-extracted cells; (e) Crude chromosome clusters; (f) Percoll-purified chromosome clusters; (g) Hexylene glycol chromosomes; (h) Spermidine chromosomes; (i) Aqueous chromosomes

and Figure $3 \mathrm{~b}$ shows the pattern for chromosome clusters purified on a Percoll density gradient. The amount of interphase (non-phosphorylated) $\mathrm{H} 1$ in the Percoll-purified clusters is reduced by at least $5-10$ times; in other words, this preparation is at least $98-99.5 \%$ metaphase chromatin. Fig. $3 \mathrm{c}$ shows the pattern for material from the top of the Percoll gradient. Most of the interphase H1 and some of the metaphase $\mathrm{Hl}$ remains there.

Two different procedures were used to purify chromosome clusters on Percoll gradients (see Materials and Methods). Both give essentially the same results. One can first isolate crude chromosome clusters and then sediment these into a preformed Percoll gradient. Alternatively, Percoll-purified clusters can be isolated in a single step by loading the cell lysate directly onto the Percoll gradient.

\section{Proteins of HeLa Metaphase Chromosome Clusters}

When the proteins of chromosome clusters purified on a Percoll gradient were analysed on dodecylsulfate/polyacrylamide gels we obtained the results shown in Fig. 4f. These can be compared with crude chromosome clusters in Fig. 4e and with hexylene glycol chromosomes, spermidine chromosomes, and aqueous chromosomes (see Materials and Methods) in Figure $4 \mathrm{~g}-\mathrm{i}$ respectively. 
The stages in the isolation of metaphase chromosome clusters are shown in Figure 4a-f. Fig. 4a shows the protein pattern of whole HeLa cells. When the metaphase HeLa cells are lysed in IB plus $0.5 \mathrm{M}$ sucrose and $0.1 \%$ NP40, and centrifuged, the proteins shown in Figure $4 \mathrm{~b}$ remain in the supernatant. The proteins of the "detergent-extracted cells" (cf. Fig. 2a) are shown in Figure $4 \mathrm{c}$. When these are homogenized and centrifuged, the proteins shown in Figure $4 \mathrm{~d}$ remain in the supernatant while the crude chromosome clusters are pelleted (Fig. 4e). The proteins of the Percoll-purified chromosome clusters are shown in Figure $4 f$.

The Percoll-purified clusters have a higher proportion of histones than the other preparations and this is probably because more contaminating cytoplasmic proteins have been removed, although we cannot exclude the possibility that Percoll strips away some true chromosomal proteins. The proteins in Figure $4 \mathrm{~b}$ are primarily the membrane proteins and soluble proteins of the cytoplasm, whereas the proteins in Figure $4 \mathrm{~d}$ are the insoluble cytoplasmic proteins. Two of the major bands in this latter group are marked by arrows in Figure 4. The larger one co-electrophoreses with actin (43K daltons) whereas the smaller one $(38 \mathrm{~K})$ cannot be identified with any known protein. It does not co-electrophorese with non-muscle tropomyosin (cf. Fine and Blitz, 1975) and is not present in human blood platelets (unpublished data). Nevertheless, these two protein bands are probably structural proteins of the cytoplasm (i.e., "cytoskeletal"), judging by their abundance. They are still present in crude chromosome clusters (Fig. 4e) and aqueous chromosomes (Fig. 4i) and to a lesser extent in hexylene glycol (Fig. $4 \mathrm{~g}$ ) and spermidine chromosomes (Fig. 4h). However, they are dramatically reduced in chromosome clusters purified on a Percoll gradient (Fig. 4f).

Even the crude chromosome clusters (Fig. 4e) have a simpler protein composition than might be expected. This may be, first, because the clusters are sedimented quickly away from the lysate, giving little time for cytoplasmic components to aggregate with the chromosomes; and second, because clusters are pelleted by a low speed spin. The higher speed needed to pellet individual chromosomes also sediments some of the larger debris.

\section{What Holds Chromosome Clusters Together?}

One of the chief questions raised by the results we have reported here is: what holds the chromosomes together in clusters? This question is of practical, as well as theoretical interest. If it were possible to release individual chromosomes from clusters, one could in principle have the advantages of the cluster isolation procedure but have individual chromosomes in the end. At present, the only clues we have toward answering this question are that hypotonic treatment of metaphase cells, or treatment with Saponin (Maio and Schildkraut, 1967) or hexylene glycol (Wray and Stubblefield, 1970) can separate the chromosomes inside the cells and thus enable them to be isolated as individual particles when the cells are lysed.

The occurrence of chromosome clusters could be explained in several ways. First, it could be a simple artefact, such as formation of disulfide bonds or 
salt bridges during the isolation. However, we have been unable to separate crude chromosome clusters into individual chromosomes by treatment with reducing agents and/or low ionic strength and EDTA.

Second, it could be a complex artefact, involving non-specific, non-covalent interactions, such as entanglement of chromatin fibres from different chromosomes, entrapment in a cytoskeletal cage, or entrapment by aggregation of other cell components with the chromosomes.

Finally, it could reflect real suprachromosomal organization in vivo. In other words, chromosome clusters could be biologically relevant entities.

This last possibility is the most intriguing, since several lines of evidence suggest that there is non-random spatial organization of the chromosomes with respect to one another in interphase nuclei and metaphase plates. Evidence for this comes from studies of the non-random occurrence of translocations in cultured lymphocytes (Welch et al. 1975), and from light microscope studies of the arrangement of chromosomes in interphase and metaphase cells (e.g., Costello, 1970; Werry et al., 1977; Ghosh and Roy, 1977; Ashley, 1979). It should be noted, however, that other careful studies have reported random arrangement of the chromosomes (see e.g., Korf and Diacumakos, 1977). Chromosome interconnections observed in the electron microscope (e.g., Bahr and Engler, 1980) have been taken as evidence of interconnections in vivo, and on the basis of such pictures DuPraw (1970) proposed that chromosomes are interconnected by continuity of their chromosomal DNA. Arguments from genetics make this seem unlikely, but end-to-end associations mediated by noncovalent protein-protein interactions are still a possibility (e.g., Ashley, 1979). On the other hand, it will be difficult to rule out the possibility that these interconnections are artefactual (see, e.g., Korf and Diacumakos, 1980) unless they occur in specific patterns.

If there are indeed well-defined spatial relationships among the various chromosomes, chromosome clusters could provide material with which to study them both structurally and biochemically. Chromosomes might not be so well organised in aneuploid cells such as HeLa, but the method should be applicable to other cells. Since clusters can be purified away from nuclei on Percoll density gradients, it would not be necessary to use highly synchronised cells for such a study.

Acknowledgements. I am grateful to A. Klug for providing the facilities in which this work was done, to $\mathrm{K}$. Lewis and U. Laemmli for introducing me to the usefulness of Percoll and for sharing their chromosome isolation methods prior to publication, and to S. Laland for his interest and encouragement.

\section{References}

Adolph, K.W.: Isolation and structural organisation of human mitotic chromosomes. Chromosoma (Berl.) 76, 23-33 (1980)

Ashley, T.: Specific end-to-end attachment of chromosomes in Ornithogalum virens. J. Cell Sci. 38, 357-367 (1979)

Bahr, G.F., Engler, W.F.: Chromosome interconnections. A discussion of their reality. Cancer Genet. Cytogenet. 1, 177-185 (1980) 
Blumenthal, A.B., Dieden, J.D., Kapp, L.N., Sedat, J.W.: Rapid isolation of metaphase chromosomes containing high molecular weight DNA. J. Cell Biol. 81, 255-259 (1979)

Costello, D.P.: Identical linear order of chromosomes in both gametes of the Acoel Turbellarian Polychoerus carmelinis: a preliminary note. Proc. nat. Acad. Sci. (Wash.) 67, 1951-1958 (1970)

Davies, K.E., Young, B.D., Elles, R.G., Hill, M.E., Williamson, R.: Cloning of a representative genomic library of the human $\mathrm{X}$ chromosome after sorting by flow cytometry. Nature (Lond.) 293, 374-376 (1981)

DuPraw, E.J.: DNA and chromosomes. New York: Holt, Rinehart and Winston 1970

Fine, R.E., Blitz, A.L.: A chemical comparison of tropomyosins from muscle and non-muscle tissues. J. molec. Biol. 95, 447-454 (1975)

Ghosh, S., Roy, S.C.: Orientation of interphase chromosomes as detected by Giemsa C-bands. Chromosoma (Berl.) 61, 49-55 (1977)

Goyannes, V.J., Matsui, S.I., Sandberg, A.A. : The basis of chromatin fiber assembly within chromosomes studied by histone-DNA crosslinking followed by trypsin digestion. Chromosoma (Berl.) 78, 123-135 (1980)

Hanson, C.V.: Techniques in the isolation and fractionation of eukaryotic chromosomes. In: New techniques in biophysics and cell biology (R.H. Pain and B.J. Smith, eds.), Vol. 2, pp. 43-84. New York: Wiley-Interscience, 1975

Horikawa, M., Sakamoto, T.: Isolation of metaphase chromosomes from synchronised Chinese hamster cells. In: Methods in cell biology, (D.M. Prescott, ed.), Vol. 15, pp. 97-109. New York: Academic Press 1977

Jeppeson, P.G.N., Bankier, A.T., Sanders, L. : Non-histone proteins and the structure of metaphase chromosomes. Exp. Cell Res. 115, 293-302 (1978)

Klobutcher, L.A., Ruddle, F.H.: Phenotype stabilisation and integration of transferred material in chromosome-mediated gene transfer. Nature (Lond.) 280, 657-660 (1979)

Korf, B.R., Diacumakos, E.G.: Random arrangement of mitotic chromosomes in radial metaphases of the Indian muntjac. Cytogenet. Cell Genet. 19, 335-343 (1977)

Korf, B.R., Diacumakos, E.G.: Absence of true interchromosomal connectives in microsurgically isolated chromosomes. Exp. Cell. Res. 130, 377-385 (1980)

Laemmli, U.K., Favre, M. : Maturation of the head of bacteriophage T4 I. DNA packaging events. J. molec. Biol. 80, 575-599 (1973)

Lund, T., Holtlund, J., Kristensen, T., Østvold, A.C., Sletten, K., Laland, S.G. : HMG17 in metaphase-arrested and interphase HeLa S3 cells. FEBS Lett. 133, 84-88 (1981)

Maio, J., Schildkraut, C.: Isolated mammalian metaphase chromosomes I. General characteristics of nucleic acids and proteins. J. molec. Biol. 24, 29-39 (1967)

Maio, J.J., Schildkraut, C.L.: Mammalian metaphase chromosomes. In: Methods in cell biology, (D.M. Prescott, ed.), Vol. 17, pp. 93-99. New York: Academic Press 1978

Marsden, M.P.F., Laemmli, U.K.: Metaphase chromosome structure; evidence for a radial loop model. Cell 17, 849-858 (1979)

Matsui, S.I., Seon, B.K., Sandberg, A.A.: Disappearance of a structural chromatin protein A24 in mitosis: Implications for molecular basis of chromosome condensation. Proc. nat. Acad. Sci. (Wash.) 76, 6386-6390 (1979a)

Matsui, S.I., Weinfeld, H., Sandberg, A.A.: Quantitative conservation of chromatin-bound RNA polymerases I and II in mitosis: Implications for chromosome structure. J. Cell Biol. 80, 451-464 (1979b)

McBride, O.W., Peterson, J.L.: Chromosome-mediated gene transfer in mammalian cells. Ann. Rev. Genet. 14, 321-345 (1980)

Paulson, J.R.: Sulfhydryl reagents prevent dephosphorylation and proteolysis of histones in isolated HeLa metaphase chromosomes. Europ. J. Biochem. 111, 189-197 (1980)

Paulson, J.R., Laemmli, U.K.: The structure of histone-depleted metaphase chromosomes. Cell 12, 817-828 (1977)

Paulson, J.R., Taylor, S.S.: Phosphorylation of histones H1 and H3 and non-histone HMG14 by an endogenous kinase in HeLa metaphase chromosomes. J. biol. Chem. 257, 6064-6072 (1982)

Pertoft, H., Laurent, T.C., Låås, T., Kågedal, L.: Density gradients prepared from colloidal silica particles coated by polyvinyl pyrrolidone (Percoll). Analyt. Biochem. 88, 271-282 (1978)

Reisfeld, R.A., Lewis, U.J., Williams, D.E.: Disk electrophoresis of basic proteins and peptides on polyacrylamide gels. Nature (Lond.) 195, 281-283 (1962) 
Stubblefield, E., Wray, W.: Architecture of the Chinese hamster metaphase chromosome. Chromosoma (Berl.) 32, 262-294 (1971)

Welch, J.P., Lee, C.L.Y., Beatty-DeSana, J.W., Hoggard, M.J., Cooledge, J.W., Hecht, F., McCaw, B.K., Peakman, D., Robinson, A.: Non-random occurrence of 7-14 translocations in human lymphocyte cultures. Nature (Lond.) 255, 241-244 (1975)

Werry, P.A.T.J., Stoffelsen, K., Engels, F.M., Laan, F. van der, Spanjers, A.W.: The relative arrangement of chromosomes in mitotic interphase and metaphase in Haplopappus gracilis. Chromosoma (Berl.) 62, 93-101 (1977)

Wray, W., Stubblefield, E. A new method for the rapid isolation of chromosomes, mitotic apparatus or nuclei from mammalian fibroblasts at near neutral pH. Exp. Cell Res. 59, 469-478 (1970)

Wullems, G.J., Horst, J. Van der, Bootsma, D.: Incorporation of isolated chromosomes and induction of hypoxanthine phosphoribosyltransferase in Chinese hamster cells. Somat. Cell Genet. 1, 137-152 (1975)

Xeros, N.: Deoxyriboside control and synchronisation of mitosis. Nature (Lond.) 194, 682-683 (1962)

Received December 17, 1981 / Accepted by D. von Wettstein 